\title{
The effects of lesion baseline characteristics and different Sr:Ca ratios in plaque fluid-like solutions on caries lesion de- and remineralization
}

\section{A R T I C L E I N F O}

Article history:

Accepted 18 August 2012

Keywords:

Fluoride

Demineralization

Remineralization

Plaque fluid

Strontium

\begin{abstract}
A B S T R A C T
This study investigated the effects of lesion baseline characteristics and different strontium (Sr) to calcium (Ca) ratios in plaque fluid-like solutions (PF) on lesion de- and remineralization. Caries lesions were formed in enamel using three protocols: methylcellulose acid gel $(\mathrm{MeC})$ and partially saturated lactic acid solutions containing carboxymethylcellulose (CMC) or not (SOLN). Lesions were exposed to PF with four distinct Sr:Ca molar ratios ${ }_{\Lambda}(0: 1 / 3: 1: 3)$, but otherwise identical composition and total $\mathrm{Sr}+\mathrm{Ca}$ molarity, for seven days. Lesions were characterized using transverse microradiography (TMR) at baseline and post-treatment. At baseline, MeC and CMC had similar integrated mineral loss values, whereas SOLN lesions were more demineralized. All lesions showed significant differences in their mineral distributions, with CMC and SOLN having lower $R$ values (integrated mineral loss to lesion depth ratio) than $\mathrm{MeC}$. Post-PF exposure, no interaction was found between lesion type and $\mathrm{Sr}: \mathrm{Ca}$ ratio. Within lesion type, $\mathrm{MeC}$ demineralized, whereas CMC and SOLN exhibited some remineralization, with the differences between $\mathrm{MeC}$ and the other lesion types being of statistical significance. Within Sr:Ca ratio, the 1:3 ratio exhibited some remineralization whereas other groups tended to demineralize. Only the difference between groups SrCa1/3 and $\mathrm{SrCaO}$ was of statistical significance. In summary, both lesion baseline characteristics and Sr:Ca ratio were shown to effect lesion de- and remineralization. Under the conditions of the study, high-R lesions are more prone to demineralize under PF-like conditions than low-R lesions. In addition, partial Sr substitution for Ca in PF was shown to enhance lesion remineralization.
\end{abstract}

(C) 2012 Published by Elsevier Ltd.

\section{Introduction}

The baseline characteristics of caries lesions have been reported to greatly affect the lesion's subsequent behaviour to de- and remineralization challenges, with the greatest impacts being attributed to baseline mineral loss $\left(\Delta Z_{\text {base }}\right)$ and $R$ value, which is ratio of $\Delta Z_{\text {base }}$ to lesion depth. Several studies ${ }^{1-}$
4 reported an increasing predisposition of lesions to net

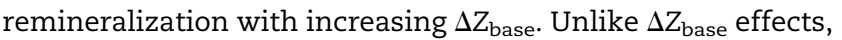
which are comparatively well understood, the effect of $R$ value has been studied to far lesser extent as the majority of investigators concentrate only on one (preferred) lesion type. Nonetheless, Lynch et al. ${ }^{5}$ found that high-R lesions are more responsive to remineralizing treatments than low- $\mathrm{R}$ lesions, presumably due to the high-R lesions' greater porosity. A very

\footnotetext{
* Tel.: +1 317274 3983; fax: +1 3172745425 .

E-mail address: flippert@iupui.edu.

0003-9969/\$ - see front matter (C) 2012 Published by Elsevier Ltd. http://dx.doi.org/10.1016/j.archoralbio.2012.08.012
}

This is the author's manuscript of the article published in final edited form as: 
recent in situ study ${ }^{6}$ found that, rather surprisingly, high- and low-R lesions showed opposite behaviours under virtually identical conditions, with the high-R lesions exhibiting some remineralization, whereas low- $\mathrm{R}$ lesions further demineralized. These studies have highlighted that more research is required in this area to further our understanding of the importance of the $R$ value.

The role of $\mathrm{Sr}$ in caries prevention has attracted great interest in the research community in the past. A number of epidemiological studies ${ }^{7-9}$ suggested that elevated $\mathrm{Sr}$ concentrations ([Sr]) in drinking water are directly correlated with decreases in caries incidence. However, the Sr caries relationship is by no means straightforward. Curzon et al. ${ }^{7}$ suggested an "optimum [Sr]", as caries incidence tended to increase (again) with increasing [Sr]. The same authors also reported differences in $\mathrm{Sr}$ response between lifelong residents and immigrants, suggesting topical and systemic Sr effects. While mechanistic studies ${ }^{10-12}$ have failed to support earlier epidemiological studies as $\mathrm{Sr}$ was shown to enhance apatite solubility as it destabilizes the apatite crystal structure, Srsubstituted apatite was, however, also shown to act as a template for nucleation and to promote apatite growth. ${ }^{13}$ Indeed, a very recent in vitro study, ${ }^{14}$ investigating remineralization of caries lesions in the presence of $\mathrm{Sr}$ and fluoride $(\mathrm{F})$, found not only synergistic $\mathrm{Sr}+\mathrm{F}$ effects but also an enhancement in lesion remineralization by Sr. An earlier in situ de-/ remineralization study ${ }^{15}$ also demonstrated superior anticaries benefits of a Sr-supplemented F dentifrice vs. a F dentifrice control (at identical [F]). While the data on $\mathrm{Sr}$ addition per se is compelling, little attention has been paid to studying lesion de- or remineralization in systems where $\mathrm{Ca}$ has been partially replaced by $\mathrm{Sr}$, as these studies would not only allow for a better evaluation of potential caries preventative effects of $\mathrm{Sr}$, but they would also provide a valuable mechanistic insight. Furthermore, it would be advantageous to study $\mathrm{Sr}$ effects under plaque fluid-like conditions, as these systems resemble most closely those found at the sites of caries occurrence.

Therefore, the aim of the present in vitro study was to study the effects of lesion baseline characteristics and different Sr:Ca ratio in PF on lesion de- and remineralization.

\section{Materials and methods}

\subsection{Enamel specimen preparation}

Enamel specimens were obtained from bovine teeth. Tooth crowns were cut into $5 \mathrm{~mm} \times 3 \mathrm{~mm}$ specimens using a Buehler Isomet low-speed saw. The teeth were stored in deionized water saturated with thymol during the sample preparation process. Specimens were ground and polished to create flat, planar parallel dentine and enamel surfaces using a Struers Rotopol 31/Rotoforce 4 polishing unit (Struers Inc., Cleveland, ${ }_{\Lambda}$ A, USA). The dentine side of the specimens was ground flat to a uniform thickness with 500-grit silicon carbide grinding paper. The enamel side of the specimen was serially ground using 1200, 2400 and 4000 grit paper. The specimens were then polished using a $1 \mu \mathrm{m}$ diamond polishing suspension on a polishing cloth until the enamel surface had a minimum of a $5 \mathrm{~mm} \times 2 \mathrm{~mm}$ highly polished facet across the specimen. Resulting specimens had a thickness range of 1.7$2.2 \mathrm{~mm}$. The specimens were assessed under the Nikon SMZ 1500 stereomicroscope at $29 \times$ magnifications for cracks, hypomineralized (white spots) areas or other flaws in the enamel surface that would exclude them from use in the study. An experimental window, measuring approximately 5 $\mathrm{mm} \times 1.7 \mathrm{~mm}$, was created on the specimens using acidresistant nail varnish (Sally Hansen Advanced Hard As Nails Nail Polish, USA), leaving sound enamel areas on either side. Prepared specimens were stored at $100 \%$ relative humidity at $4{ }^{\circ} \mathrm{C}$ until use.

\subsection{Artificial caries lesion creation}

In vitro incipient caries lesions were prepared using the following three methods as (unpublished) pilot studies revealed significant differences in the resulting lesions' mineral distributions:

For MeC, the method used by “Laboratory D" as described by ten Cate et al. ${ }^{16}$ was employed. Sound enamel specimens were demineralized at $\mathrm{pH} 4.6$ in $8 \%$ methylcellulose (aqueous, $1500 \mathrm{cP}, 63 \mathrm{kDa}$; 'M0387', Sigma-Aldrich, USA) covered with an equal volume of $0.1 \mathrm{M}$ lactic acid, $\mathrm{pH}$ adjusted with $\mathrm{KOH}$. Neither the gel nor the demineralization solution was replaced during the seven day demineralization period.

For CMC, sound enamel specimens were immersed in a demineralization solution containing $0.1 \mathrm{M}$ lactic acid, $4.1 \mathrm{mM}$ $\mathrm{Ca}\left(\right.$ as $\left.\mathrm{CaCl}_{2} \times 2 \mathrm{H}_{2} \mathrm{O}\right), 8 \mathrm{mM} \mathrm{PO}_{4}\left(\right.$ as $\left.\mathrm{KH}_{2} \mathrm{PO}_{4}\right)$ and $1 \%(\mathrm{w} / \mathrm{v})$ carboxymethylcellulose ("high viscosity", "C5013", SigmaAldrich, USA), pH adjusted to 5.0 using $\mathrm{KOH}$. The solution was not stirred or replaced during the seven day demineralization period.

For SOLN, sound enamel specimens were immersed in a demineralization solution which was identical to the one used for CMC, but lacking carboxymethylcellulose. It contained $0.1 \mathrm{M}$ lactic acid, $4.1 \mathrm{mM} \mathrm{Ca}\left(\right.$ as $\left.\mathrm{CaCl}_{2} \times 2 \mathrm{H}_{2} \mathrm{O}\right), 8 \mathrm{mM} \mathrm{PO}_{4}\left(\right.$ as $\left.\mathrm{KH}_{2} \mathrm{PO}_{4}\right)$, $\mathrm{pH}$ adjusted to 5.0 using $\mathrm{KOH}$. The solution was not stirred or replaced during the seven day demineralization period.

Lesions were created at $20 \mathrm{ml}$ gel and/or $20 \mathrm{ml}$ solution per specimen and at $37^{\circ} \mathrm{C}$.

\subsection{Transuerse microradiography (TMR)}

Sections, one per specimen and approximately $100 \mu \mathrm{m}$ in thickness, were cut from the centre of the specimens and across the lesion window and sound enamel areas after lesion creation (lesion baseline) using a Silverstone-Taylor Hard Tissue Microtome (Scientific Fabrications Laboratories, USA). Thus, a matched pair of specimens was obtained from each lesion. After sectioning, a coloured nail varnish was used to cover the cut surfaces of the specimens, serving as a reference point. Post-treatment, another section was cut from each half of the specimen and from the same side the baseline section was cut from (i.e. the coloured side). The sections were mounted, with an aluminium step wedge, on high resolution glass plate Type I A (Microchrome Technology Inc., San Jose, $\mathrm{CA}$ ) and X-rayed at $20 \mathrm{kV}$ and $30 \mathrm{~mA}$ at a distance of $42 \mathrm{~cm}$ for $65 \mathrm{~min}$. The film was developed in Kodak d-19 developer for 3 min, placed in a stop bath (Kodak 146-4247) for 45 s, and then
123 
Table 1 - Composition and chemical properties of plaque fluid-like test solutions.

\begin{tabular}{lclcl} 
& SrCaO & SrCa1/3 & SrCa1 & SrCa3 \\
\hline Lactic acid & 30 & 30 & 30 & 30 \\
$\mathrm{CaCl}_{2} \times 2 \mathrm{H}_{2} \mathrm{O}$ & 5.5 & 4.125 & 2.75 & 1.375 \\
$\mathrm{SrCl}_{2} \times 6 \mathrm{H}_{2} \mathrm{O}$ & 0 & 1.375 & 2.75 & 4.125 \\
$\mathrm{KH}_{2} \mathrm{PO}_{4}$ & 9.4 & 9.4 & 9.4 & 9.4 \\
$\mathrm{KCl}$ & 63 & 63 & 63 & 63 \\
$\mathrm{NaN}$ & 3.08 & 3.08 & 3.08 & 3.08 \\
$\mathrm{~F}($ as NaF $)$ & 1 & 1 & 1 & 1 \\
$\mathrm{pH}$ & 5.5 & 5.5 & 5.5 & 5.5 \\
$\mathrm{Sr}: \mathrm{Ca}$ molar ratio & 0 & $1 / 3$ & 1 & 3 \\
$\mathrm{DS}$ & 3.50 & 2.98 & 2.54 & 1.73 \\
$\mathrm{DS}$ & 1.12 & 0.97 & 0.84 & 0.60 \\
$\mathrm{DS}_{\mathrm{BR}}$ & 0.96 & 0.83 & 0.73 & 0.51 \\
$\mathrm{DS}_{\mathrm{FA}}$ & 14.56 & 12.41 & 10.62 & 7.22 \\
$\mathrm{DS}_{\mathrm{CaF}}$ & 0.36 & 0.33 & 0.30 & 0.24 \\
\hline $\mathrm{All}_{2}$ & & &
\end{tabular}

All concentrations are in $\mathrm{mmol} / \mathrm{l}$, except for $\mathrm{F}$ which is in $\mathrm{ppm}$.

fixed (Kodak 146-4106) for $3 \mathrm{~min}$. All plates were then rinsed in deionized water for $15 \mathrm{~min}$ and air-dried. Microradiographs were examined with a Zeiss EOM microscope in conjunction with the TMR software v.3.0.0.11. Sound enamel was assumed to be $87 \%(\mathrm{v} / \mathrm{v})$ mineral. Only lesions exhibiting an intact surface zone were included in the study. To allow for appropriate study comparisons, lesions were randomized among treatment solutions by lesion type and based on $\Delta Z_{\text {base }}$.

\subsection{Plaque fluid-like solutions (PF)}

A total of four different solutions, varying only in their $\mathrm{Sr}: \mathrm{Ca}$ molar ratios were prepared. Table 1 highlights their composition and chemical properties. Specimens were exposed to these solutions ( $20 \mathrm{ml}$ per specimen) at $37^{\circ} \mathrm{C}$ for seven days with the solutions being renewed after day three. The solutions were not stirred.

\subsection{Calculation of saturation with respect to calcium phosphate and fluoride phases}

The respective degrees of saturation with respect to hydroxyapatite $\left(\mathrm{DS}_{\mathrm{HA}}\right)$, octacalcium phosphate $\left(\mathrm{DS}_{\mathrm{OCP}}\right)$, brushite $\left(\mathrm{DS}_{\mathrm{BR}}\right)$, fluorapatite $\left(\mathrm{DS}_{\mathrm{FA}}\right)$ and calcium fluoride $\left(\mathrm{DS}_{\mathrm{CaF} 2}\right)$ of $\mathrm{PF}$ were calculated using a computer program. ${ }^{17}$

\subsection{Study variables}

For better clarity, all reported variables are summarized below: $\Delta \mathrm{Z}_{\bar{\Lambda}}$ integrated mineral loss (product of lesion depth and the mineral loss over that depth)
$L_{\Lambda}-$ lesion depth (83\% mineral; i.e. $95 \%$ of the mineral content of sound enamel)

$R_{\bar{\Lambda}}$ ratio of integrated mineral loss to lesion depth ( $\left.\Delta \mathrm{Z} / \mathrm{L}\right)$

$\mathrm{SZ}_{\max }{ }_{\Lambda}$ maximum mineral density at the lesion surface zone

$\mathrm{LB}_{\min }-$ minimum mineral density in the lesion body

Changes in variables were calculated as follows:

$\Delta \Delta Z^{*}=\Delta Z_{\text {base }} \Lambda Z_{\text {post }}$ (primary variable)

$\Delta L=L_{\text {post }} \Lambda L_{\text {base }}$
$\Delta R=R_{\text {post }}-R_{\text {base }}$

$\Delta S Z_{\text {max }}=S Z_{\text {max }}$ post $-S Z_{\text {max,base }}$

$\Delta \mathrm{LB}_{\text {min }}=\mathrm{LB}_{\text {min,post }} \boldsymbol{L B}_{\text {min, base }}$

* - indicative of remineralization if $>0$, or further demineralization if $<0$.

\subsection{Statistical analysis}

ANOVA was used to compare the effects of lesion type (MeC, CMC, SOLN) and Sr:Ca ratio $(0 ; 1 / 3 ; 1 ; 3)$ on $\Delta \Delta Z, \Delta L, \Delta R$, and $\Delta S Z_{\text {max }}$. The ANOVA models included terms for lesion type, Sr:Ca ratio, and lesion type - by -Sr:Ca ratio interaction. The software SigmaPlot 11.0 (Systat Software, Inc., Germany) was used to analyse the data.

\section{Results}

The results of the TMR analysis of lesions at baseline are given in Table 2, and the different lesions' mineral distributions are shown in Fig. 1. While MeC and CMC had similar $\Delta Z_{\text {base }}$, SOLN were more demineralized. All lesions varied in at least one parameter, with the biggest differences observed between $\mathrm{MeC}$ on one hand and CMC and SOLN on the other, especially in terms of mineral distribution. $\mathrm{MeC}$ were shallower, approximately half as mineralized in the surface zone and had a higher $R$ value than the other lesion types. SOLN were similar to CMC as both lesion types had similar R values; however, SOLN were deeper and less mineralized in the lesion body than CMC. $\mathrm{MeC}$ exhibited lesion mineral distributions representative of surface softened lesions, lacking a pronounced surface layer. Therefore, $\mathrm{LB}_{\min }$ measurements were not conducted on these lesions.

All solutions were supersaturated with respect to HA (Table 1). DS values for Sr-containing PF were lower as [Ca] were lower and as the present software did not allow for DS calculations of Sr-substituted CaPi's.

Statistical analysis of the $\Delta \Delta Z$ data revealed no interaction between lesion type and Sr:Ca ratio ( $p=0.705)$. However, both lesion type $(p<0.001)$ and Sr:Ca ratio $(p=0.039)$ were shown
179

\section{Table 2 - Lesion parameters at baseline.}

\begin{tabular}{|c|c|c|c|c|c|c|}
\hline Lesion type & $n$ & $\Delta \mathrm{Z}[\mathrm{vol} \% \% \min \times \mu \mathrm{m}]$ & $L[\mu \mathrm{m}]$ & $\mathrm{R}$ [vol.\% min] & $\mathrm{SZ}_{\max }[\mathrm{vol} \% \mathrm{~min}]$ & $\mathrm{LB}_{\min }[\% \min ]$ \\
\hline $\mathrm{MeC}$ & 22 & $2547 \pm 65^{A}$ & $74.3 \pm 2.4^{\mathrm{A}}$ & $34.7 \pm 0.9^{B}$ & $28.6 \pm 1.4^{\mathrm{A}}$ & $\mathrm{n} / \mathrm{a}$ \\
\hline CMC & 23 & $2671 \pm 82^{\mathrm{A}}$ & $96.5 \pm 2.0^{\mathrm{B}}$ & $27.7 \pm 0.7^{A}$ & $54.6 \pm 1.2^{\mathrm{B}}$ & $45.1 \pm 1.3^{\mathrm{B}}$ \\
\hline SOLN & 18 & $3238 \pm 127^{\mathrm{B}}$ & $111.8 \pm 4.7^{C}$ & $29.2 \pm 0.9^{\mathrm{A}}$ & $56.6 \pm 1.7^{\mathrm{B}}$ & $37.0 \pm 1.3^{\mathrm{A}}$ \\
\hline
\end{tabular}

The results are means \pm standard error. Different superscript letters indicate statistically significant differences within variable between lesion types $(p<0.05)$. 


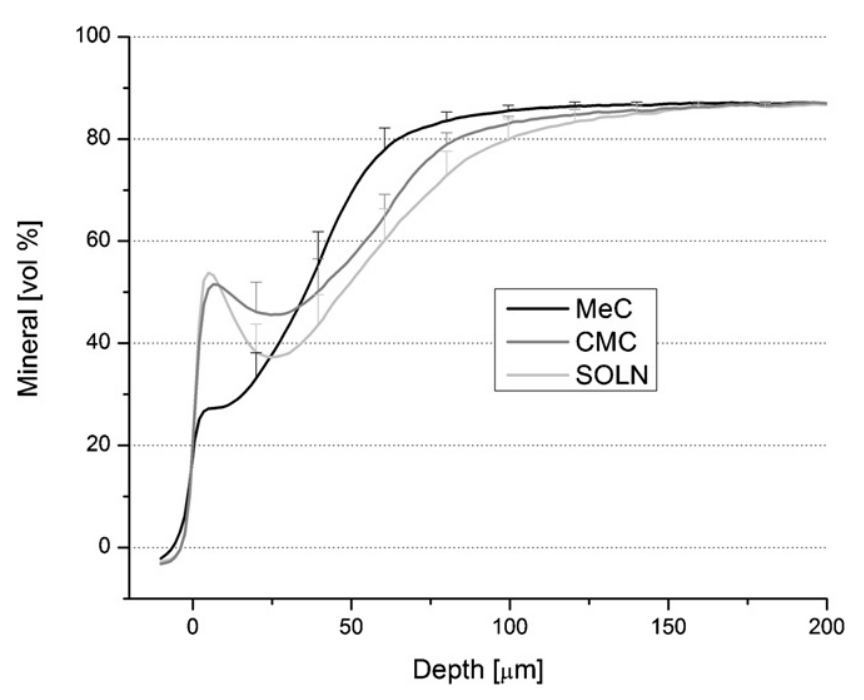

Fig. 1 - Average mineral distribution of lesions at baseline. For better clarity, error bars (standard deviations) are given at $20-\mu \mathrm{m}$ intervals.

to affect $\Delta \Delta Z$. Consequently, the data will be reported and discussed separately.

As all lesions were randomized among treatment solutions to achieve equally balanced groups with respect to $\Delta Z, L, R$ and $\mathrm{SZ}_{\max }$ only post-treatment data are shown for the Sr:Ca ratio groups. The $\Delta \Delta \mathrm{Z}$ data by lesion type and treatment are shown in Table 3. Post-treatment data for all other lesion parameters are shown in Table 4. As each lesion yielded a pair of matched specimens for the solution treatments (see "Section 2"), the
" $n$ " post-treatment should obviously be double that of baseline for each lesion type. Several specimens did, however, not yield a suitable section post-treatment; hence the sum of all post-treatment data points is lower than "baseline $n \times 2$ ".

For better transparency, $\Delta \Delta Z$ means and standard deviations are shown for all groups, despite the aforementioned lack of interaction between study factors. This was, however, omitted for the other lesion parameters as $\Delta \Delta Z$ was the primary variable. $\mathrm{MeC}$ demineralized further and also showed an increase in L. CMC and SOLN showed some remineralization, with the differences in $\Delta \Delta Z$ between $\mathrm{MeC}$ on one hand and CMC and SOLN on the other being of statistical significance. No differences in $\Delta L$ and $\Delta R$ between lesion types were found. Considering $\mathrm{SZ}_{\max }, \mathrm{MeC}$ and $\mathrm{CMC}$ exhibited an increase, whereas SOLN showed a decrease, with the difference between groups being of statistical significance. Both CMC and SOLN showed an increase in $\mathrm{LB}_{\text {min }}$ which was not different between lesion types, but of statistical significance in relation to their respective baseline values.

Figs. 2-4 show the average mineral profiles of MeC (Fig. 2), CMC (Fig. 3) and SOLN (Fig. 4) post-treatment and at baseline. No change in mineral distribution can be noted for $\mathrm{MeC}$. Demineralization appeared to occur solely beyond the original lesion. CMC exhibited some changes, as the lesion surface zone appeared to have moved inwards. Remineralization within the lesion body can be seen as well as some demineralization beyond the original lesion. SOLN also showed several changes post-treatment. Similar to CMC, the lesion surface zone moved inwards and the lesion body remineralized. However, the degree of surface zone mineralization was somewhat lower post-treatment vs. baseline.

Table 3 - Change in lesion volume $(\Delta \Delta Z)$ post-treatment for all experimental groups.

\begin{tabular}{|c|c|c|c|c|c|c|}
\hline \multirow{2}{*}{$\Lambda^{\text {Lesion type }}$} & \multicolumn{4}{|l|}{ Treatment } & \multirow[t]{2}{*}{ Means } & \multirow[t]{2}{*}{$n$} \\
\hline & $\mathrm{SrCaO}$ & $\mathrm{SrCa} 1 / 3$ & SrCa1 & $\mathrm{SrCa} 3$ & & \\
\hline $\mathrm{MeC}$ & $-457 \pm 122$ & $-85 \pm 101$ & $-247 \pm 90$ & $-198 \pm 108$ & $-247 \pm 76^{\mathrm{A}^{*}}$ & 40 \\
\hline${ }^{\wedge} \mathrm{CMC}$ & $85 \pm 207$ & $412 \pm 144$ & $44 \pm 107$ & $-134 \pm 212$ & $102 \pm 77^{B}$ & 41 \\
\hline SOLN & $44 \pm 148$ & $366 \pm 89$ & $-27 \pm 192$ & $\Lambda_{208 \pm 283}$ & $148 \pm 84^{\mathrm{B}}$ & 33 \\
\hline Means & $-109 \pm 87^{a}$ & $231 \pm 93^{b}$ & $\underline{\Lambda}_{76 \pm 89^{a b}}$ & $-42 \pm 97^{a b}$ & & \\
\hline$\hat{n}$ & 31 & 28 & 30 & 25 & & \\
\hline
\end{tabular}

The results are least square means \pm standard error. For better clarity, all $\Delta \Delta Z$ data are shown without the appropriate unit [vol.\% $\times \mu \mathrm{m}$ ]. Different superscript letters indicate statistically significant differences between lesion types (capital) and treatments (small) $(p<0.05)$. Indicates a statistically significant change from lesion baseline $(p<0.05)$.

Table 4 - Change in lesion parameters post-treatment by lesion type and treatment.

\begin{tabular}{|c|c|c|c|c|}
\hline & $\Delta \mathrm{L}[\mu \mathrm{m}]$ & $\Delta R_{\Lambda}[\mathrm{vol} . \% \mathrm{~min}]$ & $\Delta \mathrm{SZ}_{\max }[\mathrm{vol} . \% \mathrm{~min}]$ & $\Delta \mathrm{LB}_{\min }[\% \min ]$ \\
\hline \multicolumn{5}{|c|}{ Lesion type } \\
\hline $\mathrm{MeC}^{\wedge}$ & $9.0 \pm 2.0^{\mathrm{A}^{*}}$ & $-0.8 \pm 0.6^{\mathrm{A}}$ & $2.9 \pm 1.2^{\mathrm{B}}$ & $\mathrm{n} / \mathrm{a}$ \\
\hline CMC & $3.8 \pm 2.1^{\mathrm{A}}$ & $-1.8 \pm 0.6^{\mathrm{A}}$ & $3.3 \pm 1.2^{\mathrm{B}}$ & $6.0 \pm 0.9^{\mathrm{A}^{*}}$ \\
\hline SOLN & $2.5 \pm 2.3^{\mathrm{A}}$ & $1.9 \pm 0.6^{\mathrm{A}}$ & $-2.0 \pm 1.3^{\mathrm{A}}$ & $4.3 \pm 1.0^{\mathrm{A}^{*}}$ \\
\hline \multicolumn{5}{|l|}{ Treatment } \\
\hline $\mathrm{SrCaO}$ & $5.9 \pm 2.3^{\mathrm{a}}$ & $0.6 \pm 0.6^{b}$ & $0.8 \pm 1.3^{\mathrm{ab}}$ & $3.4 \pm 1.2^{\mathrm{a}}$ \\
\hline $\mathrm{SrCa} 1 / 3$ & $3.6 \pm 2.5^{a}$ & $\Lambda_{3.6 \pm 0.7^{a}}$ & $5.8 \pm 1.4^{b}$ & $7.7 \pm 1.3^{a}$ \\
\hline SrCa1 & $4.5 \pm 2.4^{\mathrm{a}}$ & $\hat{\Lambda}_{0.7 \pm 0.7^{b}}$ & $-1.4 \pm 1.3^{\mathrm{a}}$ & $5.0 \pm 1.2^{\mathrm{a}}$ \\
\hline $\mathrm{SrCa} 3$ & $6.4 \pm 2.6^{\mathrm{a}}$ & $1.1 \pm 0.7^{\mathrm{ab}}$ & $0.5 \pm 1.5^{\mathrm{ab}}$ & $4.4 \pm 1.4^{\mathrm{a}}$ \\
\hline
\end{tabular}

The results are least square means \pm standard error. Different superscript letters indicate statistically significant differences between lesion types (capital) and treatments (small) $(p<0.05)$. 


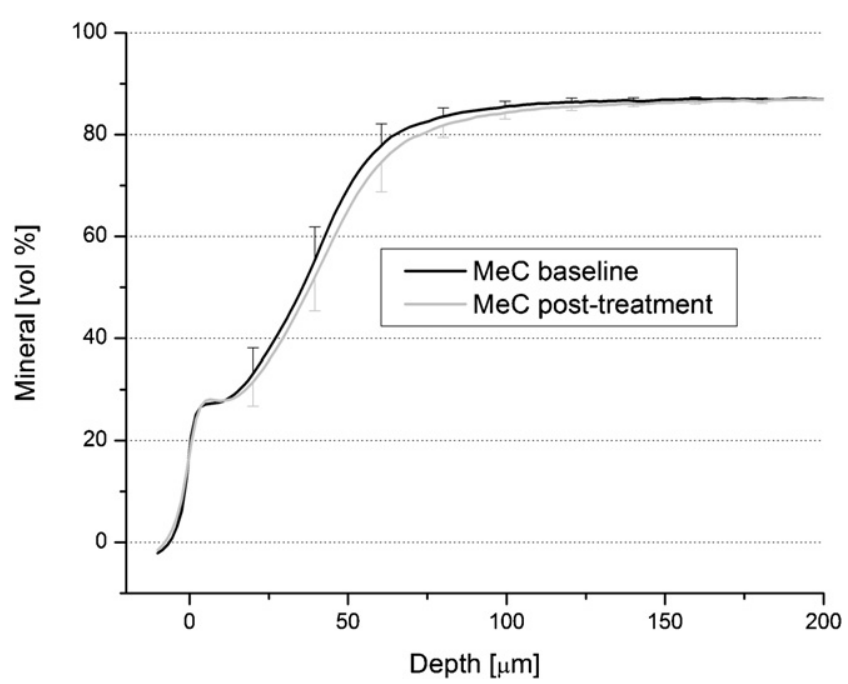

Fig. 2 - Average mineral distribution for MeC lesions at baseline and post-treatment. For better clarity, error bars (standard deviations) are given at $\mathbf{2 0}-\mu \mathrm{m}$ intervals.

Within Sr:Ca ratio, SrCa1/3 was the only group showing remineralization, whereas other groups exhibited some demineralization. SrCa1/3 was superior to $\mathrm{SrCaO}$ in terms of preventing de- and promoting remineralization. No other differences in $\Delta \Delta Z$ between groups were found. SrCa1/3 also showed (numerically) the biggest change in $\Delta R, \Delta S Z_{\max }$ and $\Delta \mathrm{LB}_{\text {min }}$. However, differences between groups in general were relatively small.

\section{Discussion}

The chosen study design of continuously exposing caries lesions to solutions of (near) constant composition is common practice in the investigation of de- and/or or remineralization

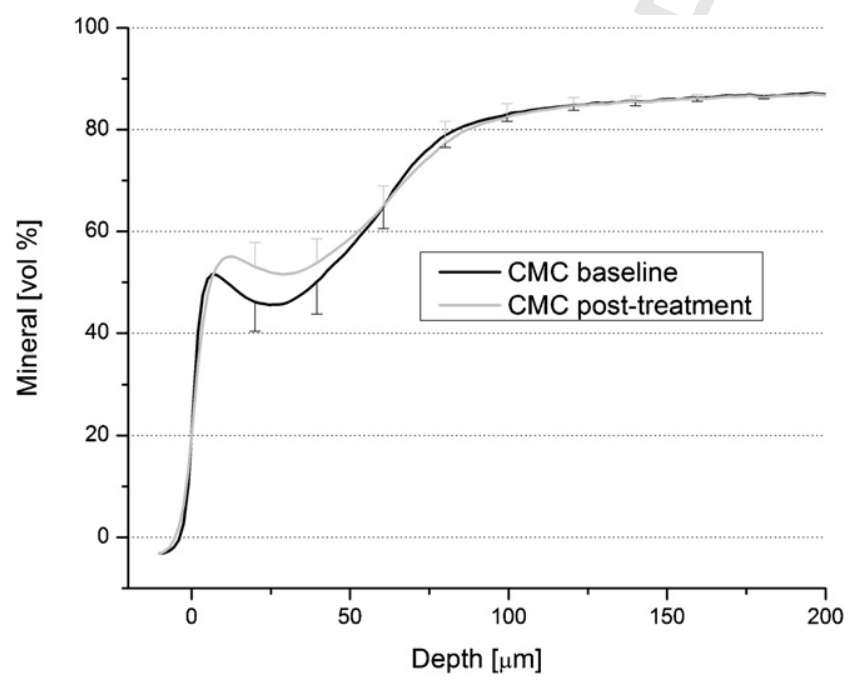

Fig. 3 - Average mineral distribution for CMC lesions at baseline and post-treatment. For better clarity, error bars (standard deviations) are given at $20-\mu \mathrm{m}$ intervals.

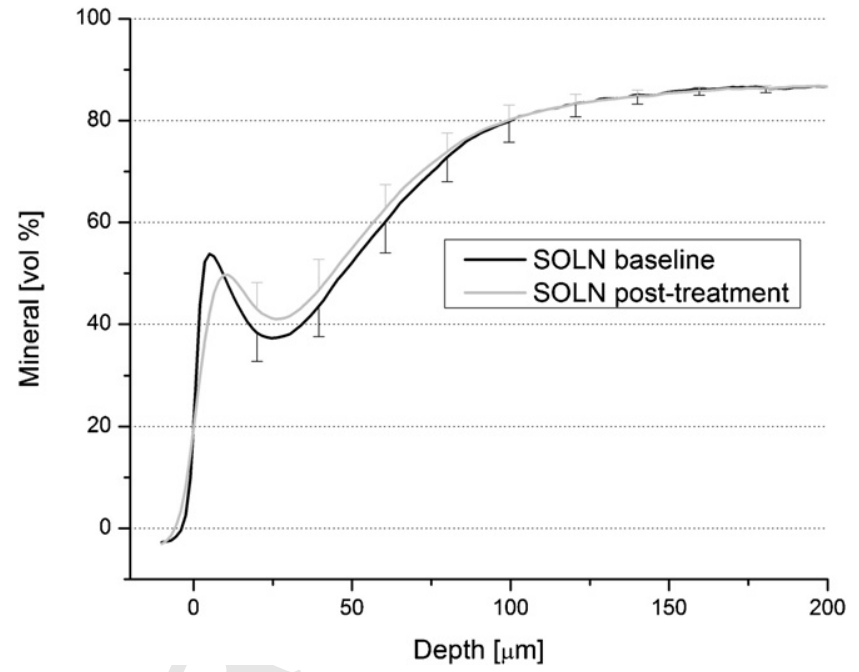

Fig. 4 - Average mineral distribution for SOLN lesions at baseline and post-treatment. For better clarity, error bars (standard deviations) are given at $20-\mu \mathrm{m}$ intervals.

processes, ${ }^{14,18,19}$ although it is, admittedly, somewhat removed from the in vivo situation, where de- and remineralization periods alternate frequently. However, these "simplistic" models allow for a better mechanistic understanding of certain facets in the caries process and are therefore justifiable. Lesion protocols were chosen based on preliminary studies. $\mathrm{MeC}$ have been employed in many previous studies, ${ }^{4,16}$ whereas CMC and SOLN were chosen to represent lesions with more pronounced although similar surface layers, yet different degrees of lesion body mineralization (Table 2). While there is no consensus among researchers with regards to what constitutes a suitable in vitro caries lesion, the three chosen protocols are representative of the broad spectrum of available laboratory lesions.

The results of the present study, with respect to the high- $\mathrm{R}$ lesion group, $\mathrm{MeC}$, are somewhat different compared to two previous studies on this lesion type - a QLF study ${ }^{20}$ employing almost identical PF formulations/solutions, and a TMR study ${ }^{18}$ using MeC-type acid gels as PF surrogates. In the previous studies, remineralization was observed in the presence of $F$, and in the study by Lynch et al. ${ }^{18}$ even at lower $\mathrm{pH},[\mathrm{Ca}]$ and [Pi]; i.e. at lower $\mathrm{DS}_{\mathrm{HA}}$ and $\mathrm{DS}_{\mathrm{FA}}$. In the present study, however, $\mathrm{MeC}$ showed demineralization. The reason for this discrepancy is not clear, especially considering that all PF were supersaturated with respect to HA and FA. Differences in the respective solubility of the bovine hard tissue samples employed may perhaps explain this discrepancy. It is worth noting that in the present study no lamination of lesions was observed (regardless of lesion type), which is in stark contrast to the study by Lynch et al. ${ }^{18}$ According to Driessens et al., ${ }^{21,22}$ laminations do not result from reprecipitation of CaPi's of lesser solubility within the lesion. They do occur, however, because the mineral is protected from local dissolution early in the process. Therefore, the lack of laminations observed in the present study may indicate that the bovine enamel substrate of the present study is inherently more soluble 
than the enamel of the earlier, aforementioned studies and therefore behaved differently. This may explain the shift towards net demineralization for $\mathrm{MeC}$ in the present study. However, one further explanation for the lack of lamination observed in the present study could be simply that the $\mathrm{PF} \mathrm{pH}$ was too high at $5.5^{23}$ (Lynch et al. ${ }^{18}$ studied in the $\mathrm{pH}$ range 4.8 5.2). In this case, no explanation for the observed discrepancy can be provided. It must also be mentioned that laminations are more likely to occur when lesions are "cycled" through alternating de- and remineralization periods. e.g.24

The results for CMC and SOLN (both low-R lesions) in comparison with $\mathrm{MeC}$ are intriguing, as the low- $\mathrm{R}$ lesions tended to remineralize, therefore showing opposite behaviour compared with $\mathrm{MeC}$. Strictly speaking, SOLN cannot be compared with $\mathrm{CMC}$ and $\mathrm{MeC}$ as differences in $\Delta \mathrm{Z}_{\text {base }}$ existed which were shown by various investigators ${ }^{3,4}$ to predispose lesions to their subsequent de-/remineralization behaviour. Regardless, $\mathrm{MeC}$ and $\mathrm{CMC}$ results are in disagreement with a recent in situ study, ${ }^{6}$ reporting that under virtually identical conditions and in the presence of $F$, high- $R$ lesions remineralize and low-R lesions further demineralize. Furthermore, Lynch et al. ${ }^{5}$ reported that high-R lesions are more responsive to remineralizing treatments than low- $R$ lesions because of the high-R lesions' greater porosity. High- and low-R lesions were somewhat comparable between all studies, although different protocols were used for low-R lesion creation in the present study, which is unlikely to be accountable for the observed discrepancy. Again, no clear explanation can be provided, as previous studies and the current knowledge of the relative importance of various lesion parameters would have predicted opposite results. To the author's knowledge, the present study was the first in vitro study comparing the response of low- and high-R lesions to $\mathrm{PF}$, clearly showing that further research is needed in this area, as at present, a discrepancy between in situ and in vitro data is evident.

Two further important aspects must be noted (a) the overall change in $\Delta Z / \Delta \Delta Z$ was relatively low (max. $10 \%$, observed for $\Lambda^{\mathrm{MeC}}$ ) and (b) the present study has been conducted on bovine enamel, whereas the discussed in situ study was conducted on human enamel. With respect to $\Lambda^{(b)}$, it is very unlikely that the choice of substrate influenced the outcome of the study as bovine and human enamel have been shown to behave similarly qualitatively but not necessarily quantitatively in many previous studies. ${ }^{4,25}$ While differences can be expected, they are most likely only of a quantitative nature. Nonetheless, extrapolation to human enamel is by no means straightforward and has to be viewed with caution, especially considering the absence of comparable in situ data on the two tissue substrates. With respect to (a), these relatively small changes (which were also observed for the Sr:Ca ratio data which will be discussed later) may potentially give rise to over-interpretation of the data. However, these differences were of statistical significance for $\mathrm{MeC}$, and further significant changes in lesion parameters and mineral distribution were observed, especially for CMC and SOLN. With respect to SOLN, it appears that the lesion surface underwent demineralization (in contradiction to $\mathrm{CMC}$ ), whereas the lesion body remineralized. As can be seen in Fig. 1, the addition of carboxymethylcellulose to the partially saturated lactic acid solution did not also reduce the amount of demineralization at baseline (in comparison to SOLN), it also produced lesions with a wider surface zone and a more mineralized lesion body, suggesting that the carboxymethylcellulose acts a "barrier", capable of retarding the lesion outward flow of $\mathrm{Ca}$ and $\mathrm{Pi}$ ions, which in turn can concentrate near the lesion surface and (re)precipitate again. As SOLN were slightly more mineralized at the surface but had a narrower surface zone than $\mathrm{CMC}$, SOLN may have been more prone for net de- rather than remineralization at the surface. This is also highlighted by the fact that the lesion surface zone move inwards for both CMC and SOLN, but not for $\mathrm{MeC}$, which were considerably less mineralized at baseline and therefore offered less mineral per se for further demineralization, and likely also mineral that was inherently less soluble.

The results for the various Sr:Ca ratios in PF tested are in line with the data reported on potential caries preventative effects of $\mathrm{Sr}$, as the partial substitution of $\mathrm{Sr}$ for $\mathrm{Ca}$ at a 1:3 molar ratio proved beneficial in retarding further demineralization and promoting remineralization of early caries lesions in comparison with the Sr-free, Ca only control. However, a further increase in the Sr:Ca ratio did only provide numerical benefits vs. Ca alone. While Sr incorporation into the apatite lattice causes an expansion in both $a$ - and c-axes ${ }^{26}$ due to Sr's larger atomic radius, ${ }^{27}$ leading to higher apatite solubility, ${ }^{12} \mathrm{Sr}$ has also the ability to stabilize apatite pre-cursor phases, such as OCP. ${ }^{28}$ Furthermore, Pan et al. ${ }^{13}$ postulated that nucleation of Sr-substituted apatite is easier than that of apatite, and that this may act as a template for apatite growth. This would explain the results of Thuy et al., ${ }^{14}$ who demonstrated enhanced in vitro remineralization of caries lesions in the presence of $\mathrm{Sr}$ and $\mathrm{F}$ compared to $\mathrm{F}$ alone. In addition, Nelson et al. $^{29}$ reported that $\mathrm{Sr}$ can at least partially offset the paracrystalline disorder in apatite induced by carbonate, and $\mathrm{Sr}$ and $\mathrm{F}$ in combination were shown to improve the crystallinity of carbonated apatite to a greater extent than by $\mathrm{Sr}$ or $\mathrm{F}$ alone, suggesting synergistic effects between $\mathrm{Sr}$ and $\mathrm{F}$ in low-carbonated apatite, which is very similar to enamel. ${ }^{30}$ Featherstone et al. ${ }^{31}$ postulated that $\mathrm{Sr}$ is incorporated into $\mathrm{Ca}$ deficient areas of enamel, which were related to carbonate inclusion. Therefore, the results of the present study are in general agreement with the aforementioned literature. The earlier proposed7 "optimum [Sr]" will, however, not be entertained as the present study was limited to one PF composition. Further work employing a wider pH range (4.975.45 has been reported for plaque fluid) ${ }^{32,33}$ and different [Ca], $[\mathrm{P}]$ and $[\mathrm{F}]$ would be required to draw such conclusions.

Structure, porosity and inherent solubility of caries lesions are important factors that determine the lesion's behaviour to de- and or remineralization challenges, ${ }^{34,35}{ }^{\wedge}$ which was elaborated on very recently. ${ }^{6}$ During lesion formation, there is preferential dissolution of the least stable fractions, especially those associated with the impurities $\mathrm{Mg}$ and $\mathrm{CO}_{3}{ }^{36}$ Within the developing lesion, this can lead to levels of supersaturation which in turn will allow (re)precipitation of mineral phases different to the original enamel mineral and possibly close to the lesion-demineralization medium interface. These mineral phases, in turn, can affect secondary deand remineralization processes. Therefore, differences in chemical composition in addition to structural differences between lesions may explain the results of the present study. 
It should also be mentioned here that a comparison between artificial caries lesions (as employed in the present study) and natural white spot lesions is not straightforward. The latter contain considerably more protein (see below), form over a substantially longer period of time (assuming similar severity) and are subject to appreciably higher fluctuations in $\mathrm{pH}$ and $\mathrm{F}$, $\mathrm{Ca}$ and Pi concentrations during their development whereas laboratory lesions are not. Likewise, differences in pore structure between and within natural and artificial caries lesions (this was not investigated in the present study) may exist depending on the rate of lesion formation, ${ }^{37}$ thereby further complicating the matter. Our understanding of these properties, processes and consequences, however, is rather poor, as highlighted recently, ${ }^{6}$ warranting further research.

One further aspect, which is rarely considered, is the role of organic material in the caries process. Previous studies ${ }^{38,39}$ were able to determine the relative distribution of proteins (predominantly salivary amylase and albumin) in various zones of white spot lesions, and albumin in particular has been postulated to affect both de- (favourably) and remineralization (adversely). ${ }^{40,41}$ Apart from exogenous proteins, endogenous proteins need to be mentioned and in particular insoluble enamel tuft proteins. These proteins are present in both human and bovine enamel and were found to be predominantly associated with the dentine-enamel junction. They are, however, also found throughout the enamel and may constitute a large part of the interprismatic organic material. ${ }^{42}$ As an initial caries attack will result mainly in mineral loss from interprismatic areas and from the prism peripheries, ${ }^{43}$ these tuft proteins may control diffusion as well as reprecipitation of mineral phases from ions dissolved at the advancing front, thereby impacting mineral distribution within the lesion. However, the endogenous organic content of lesions is unlikely to affect the overall caries process to the same extent exogenous proteins do, although comparative and or mechanistic studies in general are sparse. Furthermore, salivary or plaque-derived proteins may also play a role in lesion arrest. Their importance in lesion surface layer formation has been reported, ${ }^{44}$ and it is very likely their accumulation in caries lesions and especially near the surface can lead to a reduction in pore size and volume, thereby controlling inward and outward diffusion of ions and ultimately resulting in lesion arrest. ${ }^{45}$ Nonetheless, this area in general warrants further, clarifying research.

In general, it would have been beneficial to extend the experimental period beyond seven days, as differences between lesion types and Sr:Ca ratios may have been more pronounced. However, the extrapolation of in vitro data to the clinical situation is not straightforward as seen in the present study. Furthermore, an extension of the treatment period until considerably bigger differences could have been observed would have further limited the physiological relevance and therefore, the present results may be accurate to the extent that partial Sr for Ca substitution in PF affects de- and remineralization processes, but only to a relatively small extent.

Clearly, more research is needed to further our understanding of the impact of various lesion parameters and potential anti-cariogenic benefits of agents other than F. In conclusion, high-R lesions are more prone to demineralize under PF-like conditions than low-R lesions under the conditions of the study. In addition, partial $\mathrm{Sr}$ for $\mathrm{Ca}$ substitution in PF was shown to enhance remineralization and to retard further demineralization of early caries lesions.

$\Lambda^{\text {Funding }}$

This study was solely funded by our Institute's, Internal Hard Tissue Caries Research Progran $\Omega$

Conflict of interest statement

The author declares that there is no conflict of interest.

$\Lambda^{\text {Ethical approval }}$

Not required.

R E F E R E N C E S

1. Strang R, Damato FA, Creanor SL, Stephen KW. The effect of baseline lesion mineral loss on in situ remineralization. Journal of Dental Research 1987;66:1644-6.

2. Mellberg JR. Relationship of original mineral loss in carieslike lesions to mineral changes insitu. Caries Research 1991;25:459-61.

3. Schafer F, Raven SJ, Parr TA. The effect of lesion characteristic on remineralization and model sensitivity. Journal of Dental Research 1992;71:811-3.

4. Lynch RJM, ten Cate JM. The effect of lesion characteristics at baseline on subsequent de- and remineralisation behaviour. Caries Research 2006;40:530-5.

5. Lynch RJM, Mony U, ten Cate JM. Effect of lesion characteristics and mineralising solution type on enamel remineralisation in vitro. Caries Research 2007;41:257-62.

6. Lippert F, Zero DT, Lynch RJM, Hara AT, Eckert GJ, Kelly SA. In situ fluoride response of caries lesions with different mineral distributions at baseline. Caries Research 2011;45:47-55.

7. Curzon ME, Spector PC, Iker HP. An association between strontium in drinking water supplies and low caries prevalence in man. Archives of Oral Biology 1978;23:317-21.

8. Athanassouli TM, Papastathopoulos DS, Apostolopoulos AX. Dental caries and strontium concentration in drinking water and surface enamel. Journal of Dental Research 1983;62:989-91.

9. Curzon ME. The relation between caries prevalence and strontium concentrations in drinking water, plaque, and surface enamel. Journal of Dental Research 1985;64:1386-8.

10. LeGeros RZ. Chemical and crystallographic events in the caries process. Journal of Dental Research 1990;69:567-74. discussion 634-6 [special issue].

11. Christoffersen J, Christoffersen MR, Kolthoff N, Barenholdt O. Effects of strontium ions on growth and dissolution of hydroxyapatite and on bone mineral detection. Bone 1997;20:47-54.

12. Pan HB, Li ZY, Lam WM, Wong JC, Darvell BW, Luk KDK, et al. Solubility of strontium-substituted apatite by solid titration. Acta Biomaterialia 2009;5:1678-85.

13. Pan HB, Li ZY, Wang T, Lam WM, Wong CT, Darvell BW, et al. Nucleation of strontium-substituted apatite. Crystal Growth and Design 2009;9:3342-5.
491

492

493

494

495

496

497

498

499

501

503

504

506

507

508

509

510

511

512

513

514

515

516

517

518

519

520

521

522

523

524

525

526

527

528

529

530

531
500

502

505 
14. Thuy TT, Nakagaki H, Kato K, Hung PA, Inukai J, Tsuboi S, et al. Effect of strontium in combination with fluoride on enamel remineralization in vitro. Archives of Oral Biology 2008;53:1017-22.

15. Wefel JS, Jensen ME, Triolo PT, Faller RV, Hogan MM, Bowman WD. De/remineralization from sodium fluoride dentifrices. American Journal of Dentistry 1995;8:217-20.

16. ten Cate JM, Dundon KA, Vernon PG, Damato FA, Huntington E, Exterkate RAM, et al. Preparation and measurement of artificial enamel lesions, a four-laboratory ring test. Caries Research 1996;30:400-7.

17. Shellis RP. A microcomputer programme to evaluate the saturation of complex solutions with respect to biominerals. Computer Applications in the Biosciences 1988;4:373-9.

18. Lynch RJM, Mony U, ten Cate JM. The effect of fluoride at plaque fluid concentrations on enamel de- and remineralisation at low pH. Caries Research 2006;40: 522-9.

19. Yamazaki H, Litman A, Margolis HC. Effect of fluoride on artificial caries lesion progression and repair in human enamel: regulation of mineral deposition and dissolution under in vivo-like conditions. Archives of Oral Biology 2007;52:110-20.

20. Lippert F, Butler A, Lynch RJM. Enamel demineralization and remineralization under plaque fluid-like conditions - a QLF study. Caries Research 2011;45:155-61.

21. Driessens FC, Theuns HM, Heijligers HJ, Borggreven JM. Microradiography and electron microprobe analysis of some natural white and brown spot enamel lesions with and without laminations. Caries Research 1986;20:398-405.

22. Driessens FCM, Theuns HM, Borggreven J, Heijligers HJM. Electron-microprobe analysis and microradiography of some artificial laminated carious lesions. Caries Research 1987;21:222-7.

23. Theuns HM. The influence of in vivo and in vitro demineralising conditions on dental enamel. Thesis University of Nijmegen; 1987. p. 85-103.

24. ten Cate JM, Buijs MJ, Chaussain Miller C, Exterkate RAM. Elevated fluoride products enhance remineralization of advanced enamel lesions. Journal of Dental Research 2008;87:943-7.

25. Featherstone JD, Mellberg JR. Relative rates of progress of artificial carious lesions in bovine, ovine and human enamel. Caries Research 1981;15:109-14.

26. Collin RL. Strontium-calcium hydroxyapatite solid solutions: preparation and lattice constant measurements. Journal of the American Chemical Society 1959;81:5275-8.

27. Elliott JC. The problems of the composition and structure of the mineral components of the hard tissues. Clinical Orthopaedics and Related Research 1973;93:313-45.

28. Matsunaga K, Murata H. Strontium substitution in bioactive calcium phosphates: a first-principles study. Journal of Physical Chemistry B 2009;113:3584-9.

29. Nelson DG, Featherstone JD, Duncan JF, Cutress TW. Paracrystalline disorder of biological and synthetic carbonate-substituted apatites. Journal of Dental Research 1982;61:1274-81.
30. Featherstone JD, Shields CP, Khademazad B, Oldershaw MD. Acid reactivity of carbonated apatites with strontium and fluoride substitutions. Journal of Dental Research 1983;62:1049-53.

31. Featherstone JD, Nelson DGA, McLean JD. An electron microscope study of modifications in defective regions of dental enamel and synthetic apatites. Caries Research 1981;15:278-88.

32. Carey CM, Gregory TM, Rupp NW, Tatevossian A, Vogel GL. The driving forces in human dental plaque fluid for demineralisation and remineralisation of enamel mineral. In: Leach SA, editor. Factors relating to demineralisation and remineralisation of the teeth. Oxford: Oxford IRL Press; 1986. p. 163-73.

33. Gao XJ, Fan Y, Kent RL, Van Houte J, Margolis HC. Association of caries activity with the composition of dental plaque fluid. Journal of Dental Research 2001;80:1834-9.

34. Shellis RP. A scanning electron-microscopic study of solubility variations in human enamel and dentine. Archives of Oral Biology 1996;41:473-84.

35. Robinson C, Shore RC, Brookes SJ, Strafford SM, Wood SR, Kirkham J. The chemistry of enamel caries. Critical Reviews in Oral Biology and Medicine 2000;11:481-95.

36. Hallsworth AS, Weatherell JA, Robinson C. Loss of carbonate during the first stages of enamel caries. Caries Research 1973;7:345-8

37. Silverstone LM. Structure of carious enamel, including the early lesion. Oral Sciences Reviews 1973;3:100-60.

38. Shore RC, Kirkham J, Brookes SJ, Wood SR, Robinson C. Distribution of exogenous proteins in caries lesions in relation to the pattern of demineralisation. Caries Research 2000;34:188-93.

39. Shellis RP, Hallsworth AS, Kirkham J, Robinson C. Organic material and the optical properties of the dark zone in caries lesions of enamel. European Journal of Oral Sciences 2002;110:392-5.

40. Arends J, Schuthof J, Christoffersen J. Inhibition of enamel demineralization by albumin in vitro. Caries Research 1986;20:337-40.

41. Robinson C, Shore RC, Bonass WA, Brookes SJ, Boteva E, Kirkham J. Identification of human serum albumin in human caries lesions of enamel: the role of putative inhibitors of remineralization. Caries Research 1998;32:193-9.

42. Robinson C, Lowe NR, Weatherell JA. Amino acid composition, distribution and origin of tuft protein in human and bovine dental enamel. Archives of Oral Biology 1975;20:29-42.

43. Arends J, Jongebloed W, Ogaard B, Rolla G. SEM and microradiographic investigation of initial enamel caries. Scandinavian Journal of Dental Research 1987;95:193-201.

44. Arends J, Christoffersen J. The nature of early caries lesions in enamel. Journal of Dental Research 1986;65:2-11.

45. Teranaka T, Koulourides T, Butler WT. Protein content and amino-acid content of consolidated carious lesions in human enamel and of experimental lesions in bovine enamel exposed to the human mouth. Archives of Oral Biology 1986;31:405-10. 